Selvin, S., and Janerich, D. T. (1971). Four factors influencing birthweight. British Journal of Preventive and Social Medicine, 25, $12-16$.

Trotnow, S., Bregulla, K., and Flügel, K. (1976). Untersuchung über die Körpergrösse und das Körpergewicht con Neugeborenen in Abhängigkeit vom Paritätsstatus. Geburtshilfe und Frauenheilkunde, 36, 744-750.

\section{Complete trisomy 5p}

SIR,

In their recent report on 'Complete trisomy 5p', Brimblecombe et al. (1977) imply that the phenotype in partial trisomy $5 p$ is nonspecific, and that asymmetry of the jaw is a common finding. In our recent review on partial trisomy $5 \mathrm{p}$, we suggested that there was a recognisable and consistent phenotype based on a review of published cases and 3 additional patients of our own (DiLiberti et al., 1977). The consistent findings include a full face with the appearance of jowls, apparent ocular hypertelorism, bulbous nose, long philtrum, full lips with down-turned corners of the mouth, and mild malar hypoplasia. Asymmetry of the jaw was infrequent. It is of interest that the photograph of the patient of Brimblecombe et al. suggests most of these features and, in fact, with the exception of the ear and eye anomalies, looks remarkably like several of the young patients with partial trisomy $5 \mathrm{p}$.

Additional features present in most patients were an excess of ulnar loops, arch tibial patterns in the hallucal area, and seizures. None of these is commented upon in the current report.

Since the majority of patients with partial trisomy $5 p$ lack significant malformations, it is tempting to speculate that the extra chromosomal material distal to band p13 produces the characteristic facial appearance and retardation, and that the more proximal portion is responsible for the structural abnormalities of the eye and ear.

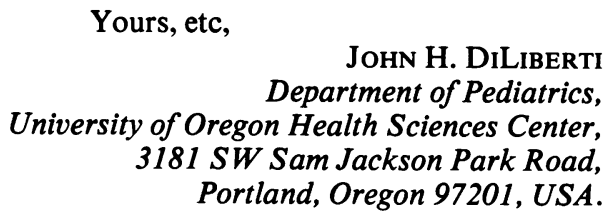

\section{References}

Brimblecombe. F. S. W., Lewis, F. J., and Vowles, M. (1977). 'Complete 5p' trisomy: 1 case and 19 translocation carriers in 6 generations. Journal of Medical Genetics, 14, 271-274.

DiLiberti, J. H., McKean, R. Webb, M. J., and Williams, G. (1977). Trisomy 5p: delineation of clinical features. Birth Defects: Original Article Series, 13, 3C, 185-194.

This letter was shown to Drs Brimblecombe and Vowles who reply as follows:
SIR,

Thank you for the opportunity to reply to the letter of Dr DiLiberti. Despite the fact that DiLiberti et al. (1977) suggest that there is a clinically indentifiable syndrome for partial trisomy $5 p$, we still maintain that there appears to be some overlap in the clinical findings described in trisomy of the short arms of chromosomes 4 and 5.

Owen et al. (1974) compared the clinical features of 1 definite and 1 probable previously described cases of trisomy of the short arm of chromosome 4 with those of their own case. Darmady and Seabright (1975) described a further case involving most of the short arm of this same chromosome. Each of these 4 cases had between 1 and 4 of the following features described by DiLiberti et al. (1977): ocular hypertelorism, bulbous nose, long philtrum, impaired mobility of elbow joints, high dermal ridge count, and mental retardation. Furthermore, they each had between 3 and 6 different features in common with our case of total trisomy 5, such as scaphocephaly, macroglossia, malformed ears, microphthalmia, narrow palpebral fissures, long fingers and toes, scoliosis, and talipes.

Tempting though it is to speculate that certain phenotypic characteristics can be assigned to different portions of the chromosome, we do not feel that this is justified as yet in the light of the above observations. Yours, etc,

F. S. W. BRIMBLECombe AND M. VoWLES Department of Paediatrics, Royal Devon and Exeter Hospital (Heavitree), Gladstone Road, Exeter EX1 2ED.

\section{References}

Darmady, J. H., and Seabright, M. A. (1975). A family with an inherited translocation involving the no. $4 /$ no. 21 chromosomes. Journal of Medical Genetics, 12, 408-411.

DiLiberti, J. H.. McKean, R., Webb, M. J., and Williams, G. (1977). Trisomy 5p: delineation of clinical features. Birth Defects: Original Article Series, 13, 3C, 185-194.

Owen, L., Martin, B., Blank, C. E., and Harris. F. (1974). Multiple congenital defects associated with trisomy for the short arm of chromosome 4. Journal of Medical Genetics, 11, 291-295.

\section{Dominance in human genetics}

The following letter from Professor E. B. Ford, FRS, arises from a definition of dominance which appears in the glossary of 'Human Genetics and Medicine' by C. A. Clarke (1977). This reads: 'Dominance: A character is said to be dominant if the gene controlling it produces the same effect in the heterozygous as in the homozygous state. Loosely, however, for clinical purposes, a condition is said to be dominant if it appears in heterozygotes. The homozygote has often never been observed'. 